\title{
CONTROL AND IDENTIFICATION OF TURBULENT BOUNDARY LAYER SEPARATION
}

\author{
Inspired by Prandtl's centennial contributions
}

\author{
Avi Seifert* and LaTunia Pack-Melton** \\ *School of Mechanical Engineering, Faculty of Engineering \\ Tel-AvivUniversity (TAU), Tel-Aviv 69978, ISRAEL (seifert@eng.tau.ac.il) \\ ** Flow Modeling and Control Branch, NASA Langley Research Center \\ Hampton,VA 23861, USA (l.p.melton@larc.nasa.gov)
}

Abstract: $\quad$ Effective delay of turbulent boundary layer separation could be achieved via closed-loop control. Constructing such a system requires that sensor data be processed, real-time, and fed into the controller to determine the output. Current methods for detection of turbulent boundary layer separation are lacking the capability of localized, fast and reliable identification of the boundary layer state. A method is proposed for short-time FFT processing of time series, measured by hot-film sensors, with the purpose of identifying the alternation of the balance between small and large scales as the boundary layer separates, favoring the large scales. The method has been validated by comparison to other criteria of separation detection and over a range of baseline and controlled flow conditions on a "simplified" high-lift system, incorporating active flow control.

Key words: Boundary layer, turbulent, separation, sensors, hot-films, closed-loop, active flow control, actuators, high-lift. 


\section{INTRODUCTION}

The identification of turbulent boundary layer separation and its control are of great practical importance [1-3]. Most applications require some sort of closed-loop control to perform efficiently, and should use knowledge of the boundary layer "state" (i.e. attached or separated and intermediate states of different degrees of complexity) over the entire separation prone region. Moreover, the knowledge as to how close the boundary layer is to separating should be updated at the highest possible rate to provide feed-back to the controller. Several flow features can be used as indicators of the "state" including, vanishing skin friction [1], local minimum of the wall pressure fluctuations [4-5] and vanishing pressure gradient [6]. The measurements techniques often used include cross-spectral information from neighboring hot-film sensors [7-12], information from the newly developed wall mounted miniature LDV system, and floating MEMS devices [3].

An appealing technique is the surface mounted hot-film, due to its simplicity, availability and low cost. Transition detection using the standard deviation alone or with either the skewness or the flatness of un-calibrated hot-film sensors is well established [7-13], as is the identification of stagnation points and laminar separation bubble using cross sensor information for identifying the "phase reversal" feature [8-13].

In a turbulent boundary layer, the phase reversal technique cannot be used for reliably determining where separation occurs. Several researchers $[\mathbf{1 1}, \mathbf{1 3}]$ have presented data using the correlation coefficient of adjacent hotfilm sensors for detecting separation. None of the above-mentioned methods were successful at determining the turbulent boundary layer separation location using the present data set. Furthermore, all methods rely on cross sensor information transfer, slowing down the loop. Therefore, the search for a new turbulent boundary layer separation detection criterion is warranted.

The subsequent sections of the paper will describe the experimental setup, the proposed criterion, the algorithm developed, and the application of the method to several data sets acquired on different configurations and at different flow conditions.

\section{EXPERIMENTAL SET-UP}

\subsection{The wind tunnel}

Tests were conducted in the Basic Aerodynamic Research Tunnel (BART), at NASA Langley Research Center. The BART facility is a low- 
speed open-circuit wind tunnel, with a $0.71 \mathrm{~m}$ high by $1.02 \mathrm{~m}$ wide by 3.05 $\mathrm{m}$ long test section. The maximum speed of the tunnel is $60 \mathrm{~m} / \mathrm{s}$ $\left(\mathrm{Re} / \mathrm{m}=0.345 \times 10^{6}\right)$. The wind tunnel is well instrumented and allows optical access for Particle Image Velocimetry (PIV) measurements.

\subsection{Simplified High-Lift Model}

The simplified high-lift version of the NASA EET (Energy Efficient Transport) airfoil model [14] was designed in a modular manner so that zero-net-mass-flux actuators could replace solid regions in the model near the leading and trailing edge flap shoulders (Fig. 1a). The $406.4 \mathrm{~mm}$ chord model has a $15 \%$ chord leading edge flap (LEF) that can be deflected from $0^{\circ}$ to $-30^{\circ}$ and a $25 \%$ chord trailing edge flap (TEF) that can be deflected from $0^{\circ}$ to $60^{\circ}$. Angle of attack settings for the airfoil, the TEF and the LEF were all automated and computer controlled. The model has 78 streamwise static pressure taps located at mid-span and two rows of 18 spanwise static pressure taps spaced $50.8 \mathrm{~mm}$ apart located at $\mathrm{x} / \mathrm{c}=0.35$ and $\mathrm{x} / \mathrm{c}=0.94$. In addition to the static pressure taps, there are nine unsteady pressure transducers on the model surface (Fig. 1b) and at least one unsteady pressure transducer embedded in each actuator cavity for monitoring the pressure fluctuations produced by the actuator and correlating the wind tunnel experiment with the bench-top actuator calibration tests. The data presented herein has not been corrected for wind tunnel wall interference.

\subsection{Hot-film Arrays}

To aid in determining the locations of transition and separation, 48 hotfilms were installed on the model. On each element (LEF, TEF, and main) of the model there are 16 hot-film sensors approximately $50.8 \mathrm{~mm}$ to the right of the model centerline (and therefore from the steady pressure tap locations, Fig. 1b). A 16-channel constant temperature anemometer coupled with a switch matrix was used to operate and acquire data from the hotfilms. The hot-films on each group of 16 elements of the model were acquired simultaneously using a 16-bit high-speed analog-to-digital converter. The data were low pass filtered at $10 \mathrm{kHz}$ and sampled at 25.6 $\mathrm{kHz}$. The films were operated at an overheat ratio of 1.2. The hot-film sensors, $0.4 \mathrm{~mm}$ long each, were etched onto a polyimide sheet and then bonded to the model. The polyimide sheet covered one half of the span of the model. A $0.1 \mathrm{~mm}$ step exists at the juncture between the polyimide sheet and the model. Body filler was used to fair the step. The frequency response of the hot-films was evaluated to be flat up to $5-7 \mathrm{kHz}$. 




Figure 1a: EET airfoil with actuators regions represented by lighter gray-level.



Figure 1b: EET pressure tap and hot-film locations, $\mathrm{c}=406.4 \mathrm{~mm}$.

\section{$2.4 \quad$ Actuators}

An internal piezoelectric fluidic actuator was used in each of the actuator regions shown in Figure 1a. The actuator slots were all inclined downstream at an angle of about $30 \mathrm{deg}$ to the surface. The flap actuator is used for the data presented in this paper. This actuator has four alternative excitation slots. Only one slot was active during each experiment. The slot located at $\mathrm{x} / \mathrm{c}=0.757$ with the TE flap un-deflected is discussed in this paper. This slot is $0.635 \mathrm{~mm}$ wide and has 19 segments that are $0.051 \mathrm{~m}$ long. The remaining slots were sealed using either a water-soluble filler or $0.051 \mathrm{~mm}$ thick adhesive Kapton tape.

\subsection{PIV Set-Up}

Digital PIV was used to measure the instantaneous flow fields, phase synchronized with the actuators' cycle. The PIV system includes two $1.3 \mathrm{k}$ by $1 \mathrm{k}$ cameras, equipped with $105 \mathrm{~mm}$ Macro lens, installed side-by-side. The field of view from each camera was overlapped to cover a larger region above the airfoil. The magnification of the imaging system was about 9:1 with the measurement plane about $70 \mathrm{~mm}$ wide. The interrogation area at each grid point had a $24 \times 24$ pixel resolution. This corresponds to about $1.5 \mathrm{~mm}$ square at the measurement plane. A maximum overlap of $50 \%$ between adjacent interrogation regions was used. Smoke (average size of 1micron), introduced upstream of the contraction, via a commercial smoke generator, was used for seeding. Dual Nd-Yag lasers were used to illuminate a light sheet, placed about $50 \mathrm{~mm}$ off the model centerline. The laser pulse separation was set at 55 microsecond to cover a free stream velocity of about 
$10 \mathrm{~m} / \mathrm{s}$. Time averaged data acquired using approximately 100 image pairs for each flow condition are presented.

\subsection{Experimental Uncertainty}

The $\alpha$ 's presented are accurate to within $\pm 0.03^{\circ}$. The LEF and TEF deflection angles are accurate to within $\pm 0.25^{\circ}, \mathrm{C} \mu$ (excitation momentum coefficient, [19]) is accurate to within $20 \%$, the chord $\mathrm{Re}$ is accurate to within $3 \%$. PIV velocity uncertainty for the current test condition is about $3 \%$.

\section{ALGORITHM}

If one examines the wall normal distribution of the turbulent eddies in an attached turbulent boundary layer [15], one finds that the smaller eddies are active close to the wall while the large eddies are active across the entire boundary layer. As the turbulent boundary layer approaches separation, due to an adverse pressure gradient, the level of the turbulent activity increases and the relative magnitude between the small and large scales, as interpreted by the spectra of the near wall velocity [5], the wall shear-stress or the wall pressure fluctuations $[4-5,16-18]$, is altered such that the lower frequencieslarger eddies contain an increasingly larger fraction of the turbulent kinetic energy. This process, however, is not steady [16], but intermittent. Our physical interpretation of these findings is that at incipient detachment, the small but still energy containing eddies will stop interacting with the wall in an intermittent manner. The largest scales would still interact with the wall even when the flow is mostly separated, affecting the attached flow periods, and therefore, also reinstating the high frequency content of the measured wall mounted sensor signal. Hence, a flow separation criterion was developed, that is based on the intermittent disappearance of the high frequency content from the spectra of a hot-film sensor signal. This criterion does not require cross sensor information exchange and could hopefully be used also in complex 3D flows.

The method is constructed of the following steps:

1. Short time FFT (STFFT) of the hot-film voltage time history,

2. High-pass filtering of the FFT coefficients, above a predetermined cross-over frequency (to be defined below),

3. Summation of the high frequency coefficients to generate the "high-frequency standard deviation" (HFSDV) of the signal,

4. Time averaging of all the HFSDV's calculated in step 3,

5. Normalizing the time dependent HFSDV's by their mean, 
6. Calculating the standard deviation of the normalized HFSDV.

The crossover frequency $\left(f_{c}\right)$ was selected based on interrogation of a large number of data sets to be $f_{c} / U e \approx 5$, where $U e$ is the velocity at the boundary layer edge, calculated from the pressure distribution. The result of the above procedure is independent of the flow conditions due to the auto normalization. Time windows of $40 \mathrm{~ms}$ were currently used, at the current low speed conditions, but it can be significantly shorter especially at higher speeds. A threshold level of 0.225 was found to be adequate for identifying baseline as well as controlled separation over a wide range of configurations and Reynolds numbers.

The addition of large or small-scale coherent structures [19-23], for the purpose of controlling the turbulent boundary layer separation, complicates the separation identification procedure, by adding coherent motion to the complex separating boundary layer spectra. However, a separation of scales exists between the small-scale motion, which the current criterion searches for its disappearance, and the excitation imposed large-scale structures. The method also performed well when high frequency excitation was introduced, due to the high dissipation rate of these scales.

\section{RESULTS}

\subsection{Baseline and controlled flow}

Due to the limited scope of the current paper, only one flow condition will be described in detail. Fig. 2 describes the pressure distributions on the baseline and controlled flows. The model is at incidence of $\alpha=6^{\circ}$, the leading and trailing edge flaps are deflected $-25^{\circ}$ and $20^{\circ}$, respectively and the chord Reynolds number, $\mathrm{Re}_{\mathrm{c}}$, is $0.24 \times 10^{6}$.

The baseline flow separates at $x / c \approx 0.8$, i.e. slightly downstream of the deflected flap shoulder, based on the vanishing pressure gradient criterion. When high frequency excitation at rather high momentum coefficient, $\mathrm{C} \mu \approx 1.0 \%$, was applied from the flap actuator slot, located at $\mathrm{x} / \mathrm{c}=0.77$ $\left(\delta_{\mathrm{f}}=20^{\circ}\right)$, the flow partly reattached to the flap. This actuation resulted in delayed separation and increased circulation around the entire airfoil. The lift coefficient was increased in this case from 1.65 to 1.82 while the form-drag coefficient increased from 0.074 to 0.078 . 


\subsection{Application of the algorithm}

The mean wall pressures $(\mathrm{Cp})$ could only provide an indirect indication of the location of the mean separation location. A more direct indication of the mean separation location can be obtained from analyzing the PIV measured streamwise velocities presented in Figures $3 \mathrm{a}$ and $3 \mathrm{~b}$, for the baseline and controlled flows, respectively. Note the seam between the two partly overlapping images acquired simultaneously by the two PIV cameras. One should take into account the wall normal averaging of the PIV technique, due to the interrogation cell size. The PIV data indicates, using the zeroing of the near wall velocity [1] as guidance, that the baseline flow separates at $\mathrm{x} / \mathrm{c}=0.78$. According to the same criterion, separation is delayed to $\mathrm{x} / \mathrm{c}=0.87$, using the control input.

Applying the separation detection criterion based on the hot-film signals and using the suggested threshold level of 0.225, as shown in Fig. 4, indicates that the baseline flow separates at $\mathrm{x} / \mathrm{c}=0.78$ and that separation is delayed to $\mathrm{x} / \mathrm{c}=0.87$ in the controlled flow. The agreement between the $\mathrm{Cp}$, the PIV data and the new separation detection criterion is satisfactory, validating the criterion. The criterion was validated also at different $\operatorname{Re}_{\mathrm{c}}$ and LEF and TEF deflections and excitation locations [23].

Sensitivity tests for the sampling rate, STFFT window width, low pass filter setting to simulate a lower band-width sensor, and threshold levels were conducted and resulted in low sensitivity.

\section{CONCLUSIONS}

A new turbulent boundary layer separation detection method has been proposed, formulated and validated using experimental data obtained over the NASA-TAU "simplified high-lift system".

The method makes use of the changing balance between small and largescale turbulent structures, favoring the large scale, as the boundary layer separates. Raw surface mounted hot-film sensor data was acquired and analyzed. The method and the separation detection criterion were validated using mean pressures and PIV data over a range of Reynolds numbers, geometries, and excitation locations.

Further study is required in order to enable the use of the new method and criterion as part of a closed-loop active separation control system, with the aim of efficient-distributed control of turbulent boundary layer separation. 


\section{ACKNOWLEDGEMENTS}

The authors would like to express their gratitude to the following for substantial support in the reported research: I. Fono (TAU), W. L .Sellers, M. J. Walsh, A. E. Washburn, L. N.

Jenkins, R. D. White, G.C. Hilton, J. Mau, L. M. Hartzheim, S. O. Palmer, R. D. Lewis, and A. R. McGowan.

\section{REFERENCES}

1. Prandtl, L. (1904, Translation: Motion of Fluids with Very Little Viscosity, NACA TM 452, 1928).

2. Chang, P.K.: Control of Flow Separation: Energy Conservation, Operation Efficiency, and Safety, Hemisphere Publishing Corporation, 1976.

3. Gad-El-Hak, M.: Flow Control, Passive, Active and Reactive Flow Management. Cambridge University Press, August, 2000.

4. Na, Y. and Moin, P.: Direct Numerical Simulation of a Separated Turbulent Boundary Layer. J. of Fluid Mech., Vol 374, pp. 379-405, 1998.

5. Simpson, R.L., Ghodbane, M., McGrath, B.E.: Surface Pressure Fluctuations in a Separating Turbulent Boundary Layer, J. Fluid Mech., 177, pp. 167-186, 1987.

6. Allan, B.G.,Jer-Juang,N.,Raney,D.,Seifert,A.Pack,L.G., Brown,D.E.: Closed-loop separation control using oscillatory flow excitation, ICASE Report 2000-32,2000.

7. Bertelrud, A..: Transition on a Three-Element High Lift Configuration at High Reynolds Numbers, AIAA paper 98-0703, January 1998.

8. Nakayama, A., Stack, J.P., Lin, J.C., and Valarezo, W.O.: Surface Hot-Film Technique for Measurements of Transition, Separation, and Reattachment Points, AIAA paper 93-2978, July 1993.

9. Stack, J.P., Mangalam, S.M., and Kalburgi, V.: The Phase Reversal Phenomenon at Flow Separation and Reattachment, AIAA paper 88-0408, 1988.

10. Hausmann, F., Schröder, W. and Limberg, W.: Development of a Multi-Sensor Hot-film Measuring Technique for Transition Detection in Cruise Flight, AIAA paper 2002-0534.

11. Meijering, A. and Schröder, W.: Experimental Analysis of Separated and Transonic Airfoil Flow, AIAA paper 2001-2987. June 2001.

12. Lee, T. and Basu, S.: Nointrusive Measurements of the Boundary Layer Developing on a Single and Two Circular Cylinders, Exp. in Fluids, Vol. 23, pp. 187-192 Springer-Verlag, 1997

13. Krause,E.,Abstiens,R.,Fuhling,S.,Vetlutsky,V.N.: Boundary-layer investigations on a model of the ELAC 1 configuration at high Reynolds numbers in the DNW, Eur. J. Mech. B-Fluids, 19, pp. 745-764, 2000.

14. Lin, J.C. and Dominik, C.J.: Parameteric Investigation of a High-Lift Airfoil at High Reynolds Numbers, AIAA J., Vol. 34, No. 4, 1997, pp. 485-491.

15. Klebanoff, P.S.: Characteristics of Turbulence in Boundary Layer with Zero Pressure Gradient. NACA Report 1247, 1955.

16. Simpson, R. L.: Turbulent Boundary Layer Separation, Ann. Rev. Fluid Mech., pp 205-234, 1989. 
17. Na, Y. and P. Moin: The Structure of Wall-Pressure Fluctuations in Turbulent Boundary Layers with Adverse Pressure Gradient and Separation, J. Fluid Mech., Vol. 377, pp. 347-373, 1998.

18. Simpson, R.L., Chew, Y.-T., and Shivaprasad, B. G.: The Structure of a Separating Turbulent Boundary Layer. Part 2. Higher-Order Turbulence Results. J. Fluid Mech., 113, pp. 53-73, 1981.

19. Seifert, A. and Pack, L.G.: Oscillatory Control of Separation at High Reynolds Numbers. AIAA J., Vol. 37, No. 9, 1999 pp. 1062-1071.

20. Seifert, A. and Pack, L.G.: Active Flow Separation Control on Wall-Mounted Hump at High Reynolds Numbers. AIAA J., Vol. 40, No. 7, July 2002, pp. 13631372.

21. Pack, L.G., Schaeffler, N.W., Yao, C.S., and Seifert, A.: Active Control of Separation from the Slat Shoulder of a Supercritical Airfoil. AIAA paper 02-3156, June 2002. Submitted to AIAA J. of Aircraft, April 2004.

22. Pack, L.G., Yao, C.S., and Seifert, A.: Active Control of Separation from the Flap Shoulder of a Supercritical Airfoil. AIAA paper 03-4005, June 2003. Submitted to AIAA Journal, July 2004.

23. Pack Melton, L., Yao, C.S., and Seifert, A., Application of Excitation from Multiple Locations on a Simplified High-Lift System, AIAA Paper 2004-2324, June 2004.

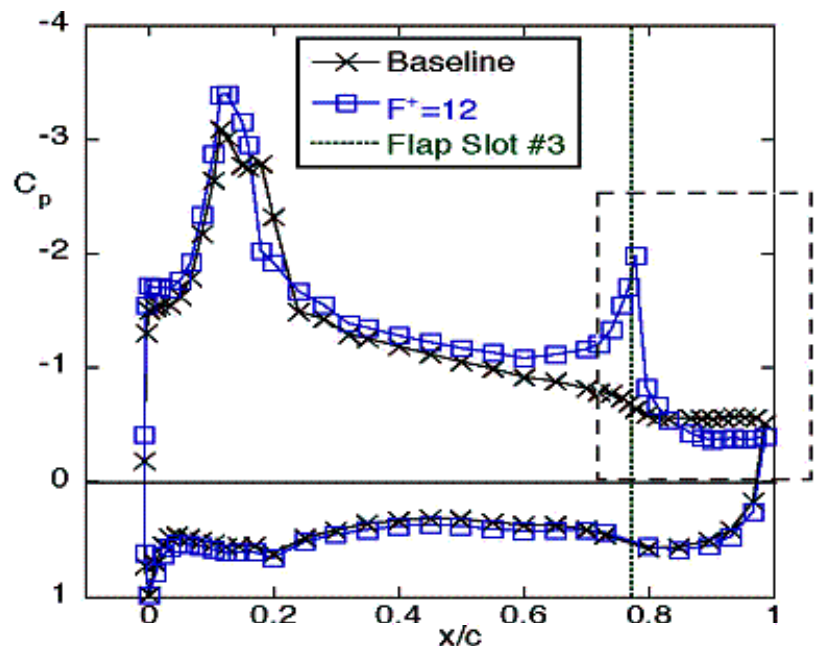

Fig. 2 Pressure distributions of baseline and controlled flow [19]. Dashed box indicates PIV interrogation region of Figures 3. 


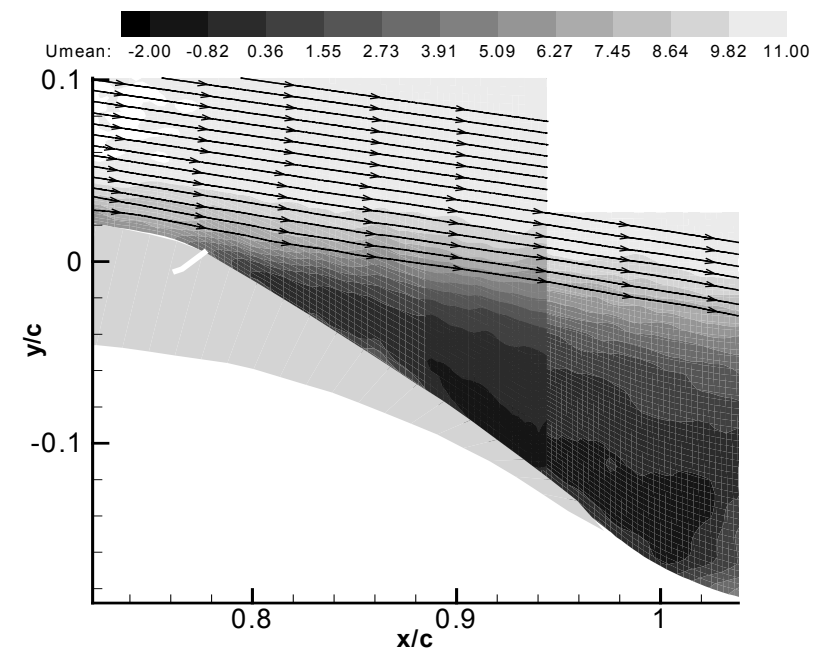

Fig. 3a PIV data of the flow above the baseline deflected flap (dashed region in Fig. 2).

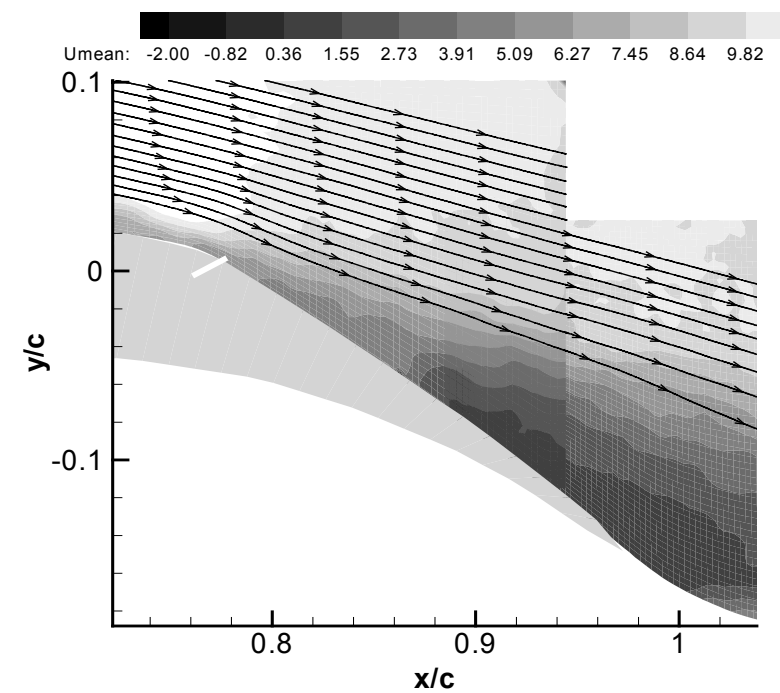

Fig. 3b PIV data of the flow above the controlled deflected flap (dashed region in Fig. 2). 


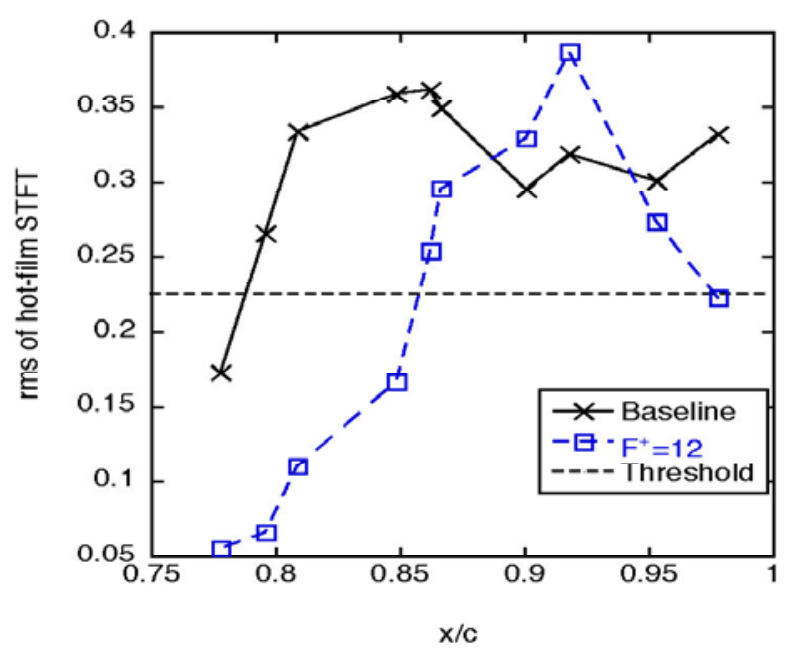

Fig. 4 Separation location based on a threshold level of 0.225 for the flow conditions of Figures 1-3. 